\section{BRAZIULIAN JOURNAL}

OF MEDICAL AND BIOLOGICAL RESFARCH

www.bjournal.com.br
ISSN 0100-879X

Volume 43 (8) 698-811 August 2010

BIOMEDICAL SCIENCES

AND

CLINICAL INVESTIGATION

Braz J Med Biol Res, August 2010, Volume 43(8) 786-793

doi: 10.1590/S0100-879X2010007500071

Effect of oral sirolimus therapy on inflammatory biomarkers following coronary stenting

W.C.M. Rosa, A.H. Campos and V.C. Lima

The Brazilian Journal of Medical and Biological Research is partially financed by
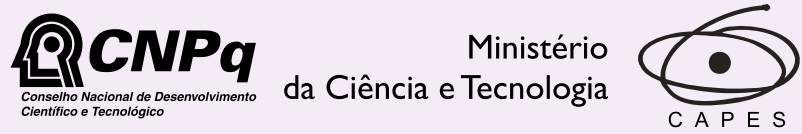

Ministério da Educação

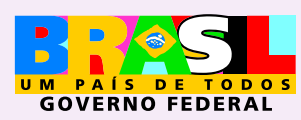

DFAPESP

Institutional Sponsors
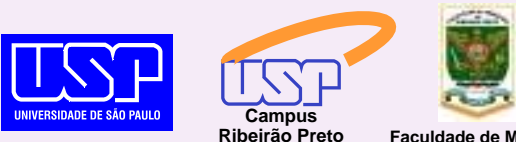

Ф SHIMADZU

GE Healthcare
Hotsite of proteomics metabolomics developped by: 


\title{
Effect of oral sirolimus therapy on inflammatory biomarkers following coronary stenting
}

\author{
W.C.M. Rosa ${ }^{1,2}$, A.H. Campos ${ }^{1}$ and V.C. Lima ${ }^{1}$ \\ ${ }^{1}$ Disciplinas de Cardiologia e Nefrologia, Hospital São Paulo and Hospital do Rim e Hipertensão, \\ Universidade Federal de São Paulo, São Paulo, SP, Brasil \\ 2Disciplina de Cardiologia, Hospital Universitário Cassiano Antonio de Morais, \\ Universidade Federal do Espírito Santo, Vitória, ES, Brasil
}

\begin{abstract}
We studied the effect of oral sirolimus, administered to prevent and treat in-stent restenosis (ISR), on the variation of serum levels of inflammatory markers following coronary stenting with bare metal stents. The mean age of the patients was $56 \pm 13$ years, $65 \%$ were males and all had clinically manifested ischemia. Serum levels of high sensitivity C-reactive protein (hs-CRP) concentration were determined by chemiluminescence and serum levels of all other biomarkers by ELISA. One group of patients at high risk for ISR received a loading oral dose of $15 \mathrm{mg}$ sirolimus and $5 \mathrm{mg}$ daily thereafter for 28 days after stenting (SIR-G). A control group (CONT-G) was submitted to stenting without sirolimus therapy. The increase in hs-CRP concentration was highest at $24 \mathrm{~h}$ after stenting in both groups. A significant difference between SIR-G and CONT-G was observed at 4 weeks $(-1.50 \pm 5.0$ vs $-0.19 \pm 0.4, P=0.008)$ and lost significance 1 month after sirolimus discontinuation $(-1.73 \pm 4.3$ vs $-0.01 \pm 0.7$, $\mathrm{P}=0.0975)$. A continuous fall in MMP-9 concentration was observed in SIR-G, with the greatest reduction at 4 weeks $(-352.9$ $\pm 455 v s+395.2 \pm 377, P=0.0004)$, while a positive variation was noted 4 weeks after sirolimus discontinuation ( $227 \pm 708$ vs $406.2 \pm 472.1, P=0.0958)$. SIR-G exhibited a higher increase in P-selectin after sirolimus discontinuation at week 8 (46.1 \pm 67.9 vs $5.8 \pm 23.7, P=0.0025)$. These findings suggest that the anti-restenotic actions of systemic sirolimus include anti-proliferative effects and modulation of the inflammatory response with inhibition of adhesion molecule expression.
\end{abstract}

Key words: Inflammation mediators; Oral sirolimus; Percutaneous coronary intervention; Coronary artery angioplasty; Coronary restenosis; Immunosuppression

\section{Introduction}

It is well known that coronary artery angioplasty and stenting are both associated with local vascular and systemic inflammation (1-4), which in turn correlate with increased restenosis after percutaneous coronary interventions $(\mathrm{PCI})$ (5-7). However, the nature of the inflammatory response to coronary artery stenting is different from that associated with balloon angioplasty, and the specific biological response to stent injury is strongly associated with intimal smooth muscle cell migration/proliferation that culminates in in-stent restenosis (ISR) (8).

Because of the specific characteristics of the inflammatory response to different types of injury, different drugs and drug regimens for the treatment of restenosis may produce diverse effects. Sirolimus is an immunosuppressant agent with anti-proliferative, anti-migratory and anti-inflammatory properties (9) and is FDA-approved for the prophylaxis of renal transplantation rejection in the United States (10).
More recently, sirolimus has been used to prevent ISR with a coated stent design with good clinical and angiographic results (11).

A number of clinical studies have tested oral sirolimus to prevent or to treat ISR. Despite having studied highly heterogeneous patient groups and drug regimens, these studies have shown a significant reduction of angiographic ISR (12-15). The aim of the present study was to characterize the systemic response of biomarkers known to be involved in the vascular response to coronary stenting and determine if oral sirolimus has any effect on the behavior of these biomarkers.

\section{Material and Methods}

The following biomarkers were evaluated: high sensitivity C-reactive protein (hs-CRP), soluble interleukin-2

Correspondence: W.C.M. Rosa, Setor de Hemodinâmica e Cardiologia Intervencionista, HUCAM, Av. Marechal Campos s/n, 29042-755 Vitória, ES, Brasil. Fax: +55-27-3335-7314. E-mail: wcmrosa@terra.com.br

Received December 9, 2009. Accepted June 10, 2010. Available online July 30, 2010. Published August $13,2010$. 
receptor alpha (IL-2sR $\alpha$ ), monocyte chemoattractant protein-1 (MCP-1), matrix metalloproteinase 2 (MMP-2), matrix metalloproteinase 9 (MMP-9), tissue inhibitor of MMP-1 (TIMP-1), intercellular adhesion molecule-1 (ICAM$1)$, and P-selectin.

\section{Patient population}

Three groups of patients were compared. The sirolimustreated group (SIR-G) comprised 11 patients treated with oral sirolimus one day before and 28 days after stenting and who had been enrolled in a previous study (13). These patients were at high risk for developing ISR, with 17 lesions in native coronary arteries (9 de novo and 8 ISR), without angina or documented ischemia. The control group (CONTG) contained 12 consecutive patients, matched for gender and age to the SIR-G, who underwent coronary stenting and were not treated with sirolimus. These patients underwent $\mathrm{PCl}$ for 15 de novo lesions in native vessels. The reference group (REF-G) included 25 healthy volunteers with very low probability of coronary artery disease recruited to provide biomarker reference levels. The clinical and angiographic characteristics of the participants are reported in Table 1.

\section{Study protocol and pharmacological regimens}

The study protocol, which is in accordance with the 1975 Declaration of Helsinki, was approved by the Research Ethics Committee of Hospital São Paulo and Hospital do Rim e Hipertensão, Universidade Federal de São Paulo. Written informed consent was obtained from each patient. SIR-G and CONT-G patients underwent PCI with coronary stenting according to standard techniques. Intra-coronary nitroglycerin $(300 \mu \mathrm{g})$ was given before the angiograms. The

Table 1. Baseline clinical and angiographic characteristics.

\begin{tabular}{lrcc}
\hline Characteristic & $\begin{array}{c}\text { Sirolimus } \\
(\mathrm{N}=11)\end{array}$ & $\begin{array}{c}\text { Control } \\
(\mathrm{N}=12)\end{array}$ & $\begin{array}{c}\text { Reference } \\
(\mathrm{N}=25)\end{array}$ \\
\hline Age (mean \pm SD, years) & $56.8 \pm 13$ & $55.3 \pm 13$ & $29.4 \pm 8$ \\
Male gender & $8(75 \%)$ & $7(58 \%)$ & $11(44 \%)$ \\
Hypertension & $10(91 \%)$ & $7(58 \%)$ & 0 \\
Diabetes & $5(42 \%)$ & $4(33 \%)$ & 0 \\
Chronic renal failure & $3(17 \%)$ & $1(8 \%)$ & 0 \\
Acute coronary syndrome & $5(45 \%)$ & $5(42 \%)$ & 0 \\
Stable angina & $6(54 \%)$ & $7(58 \%)$ & 0 \\
Lesions treated & 18 & 15 & - \\
$\quad$ LAD & $9(50 \%)$ & $5(33 \%)$ & - \\
LCX & $4(22 \%)$ & $3(20 \%)$ & - \\
RCA & $5(28 \%)$ & $7(47 \%)$ & - \\
In-stent restenosis & $8(44 \%)$ & 0 & - \\
\hline
\end{tabular}

Data are reported as number with percent in parentheses, unless otherwise indicated. $L A D=$ left anterior descending artery; $L C X=$ left circumflex artery; RCA = right coronary artery.
SIR-G and CONT-G groups received a loading dose of 300 $\mathrm{mg}$ clopidogrel $6 \mathrm{~h}$ before the procedure and $75 \mathrm{mg}$ daily for 30 days after $\mathrm{PCI}$. SIR-G patients received a loading dose of $15 \mathrm{mg}$ sirolimus the day before the procedure followed by $5 \mathrm{mg}$ daily for 28 days. Whole blood concentrations of sirolimus were measured weekly by ultraviolet wavelength high performance liquid chromatography (HPLC/UV) (16), and the drug dose was adjusted to maintain a whole blood concentration of $10-15 \mathrm{ng} / \mathrm{mL}$.

Venous blood for biomarker protein measurements were collected at similar times from both SIR-G and CONT-G: the day before the procedure, $24 \mathrm{~h}$ after the procedure, and 1, 4, and 8 weeks thereafter. Samples were collected only once for patients in the REF-G. After centrifugation, serum was separated and divided into small aliquots, one for each biomarker assayed, and stored at $-85^{\circ} \mathrm{C}$.

Patients in the experimental groups were followed weekly for 8 weeks. Hematological tests, urea, creatinine, total cholesterol and its fractions, and triglycerides were measured weekly in SIR-G patients up to the 4th week and 4 weeks after drug discontinuation (8th week). Significant thrombocytopenia ( $<100,000$ platelets/dL) and/or leukopenia ( $<3000$ white blood cells/dL) were criteria for drug discontinuation.

\section{Laboratory assays}

hs-CRP concentration was determined by chemiluminescence (Immulite, DPC Labs, USA). Intra- and interassay coefficients of variation for hs-CRP measurement were less than 6.4 and 10\%, respectively. MMP-2, MMP-9 and $P$-selectin were assayed by enzyme-linked immunosorbent assay (ELISA) with a commercially available kit (Quantikine HS Human, R\&D Systems, USA). The detection limits were $0.16 \mathrm{ng} / \mathrm{mL}$ for MMP-2, $0.156 \mathrm{ng} / \mathrm{mL}$ for MMP-9 and 0.5 $\mathrm{ng} / \mathrm{mL}$ for P-selectin. Intra- and interassay coefficients of variation were less than 3 and $8 \%$ for MMP-9, and less than 6 and $10 \%$ for MMP-2 and P-selectin, respectively. IL-2sRa, MCP-1, TIMP-1, and ICAM-1 were also measured with ELISA kits (DuoSet ELISA development system, R\&D Systems) with detection limits of $0.031,0.015,0.031$, and $0.015 \mathrm{ng} / \mathrm{mL}$, respectively. Intra- and interassay coefficients of variation were less than $10 \%$ in both cases for these biomarkers. All ELISA measurements were done in duplicate. Difference in duplicate was always less than $10 \%$.

\section{Data presentation and statistical analysis}

Data are reported as means \pm SD. Baseline values of all biomarkers were defined as the absolute levels measured before the coronary interventions. At follow-up, the changes in the levels of biomarkers in relation to baseline values (deltas) were computed for each time. ANOVA was used for comparisons between groups at baseline; if differences were found, the Tukey test was applied for multiple comparisons. At follow-up, changes from baseline at 4 times (24 h, 1 week, 4 weeks, 8 weeks) were evaluated using a 
mixed-model repeated measures analysis of variance with Kenward-Roger correction for degrees of freedom. In the presence of statistically significant time vs group interactions, tests of simple effects were used to test the group effect at each time. To help visualize the interaction, plots of group $v s$ time least-squares means with $95 \%$ confidence intervals were generated. Additionally, because of the nonrandomized nature of the study, SIR-G and CONT-G groups were compared at each time by analysis of covariance (ANCOVA) models with adjustment for values of biomarkers before the stent implantation - baseline levels - in order to correct for intrinsic differences between the two groups.

All statistical analyses were performed using the SAS software (version 9.2; SAS Institute, Inc., USA). All P values are two-sided. A $P$ value $<0.05$ was considered to be significant while a $P$ value $<0.10$ and $\geq 0.05$ was considered to be marginally significant.

\section{Results}

\section{Whole blood concentration of sirolimus and side effect monitoring}

The mean whole blood sirolimus concentrations in SIR-G were $13.6 \pm 9.6 \mathrm{ng} / \mathrm{mL}$ at week $1,18.3 \pm 9.2 \mathrm{ng} / \mathrm{mL}$ at week 2, $14 \pm 8.2 \mathrm{ng} / \mathrm{mL}$ at week 3 , and $13.4 \pm 6.7 \mathrm{ng} / \mathrm{mL}$ at week 4 . Daily doses were reduced in 5 patients to keep the target blood levels. The treatment was well tolerated by all patients, and only minor side effects were observed, including acne (1 patient), conjunctivitis (1 patient), and stomatitis (4 patients). All side effects were reversed after the discontinuation of sirolimus.

\section{Baseline biomarker measurements}

SIR-G patients had higher baseline levels of MMP-9 and TIMP-1 (Table 2) and CONT-G patients had higher baseline levels of ICAM-1. The other biomarkers did not differ significantly between SIR-G and CONT-G groups at baseline.

\section{Biomarker measurements after 24 h, 1, 4, and 8 weeks}

The variation $(\Delta)$ of each biomarker for SIR-G and CONT-G patients is presented in Table 2 and Figure 1. The most important findings are identified below.

hs-CRP. The concentration of serum hs-CRP was higher in SIR-G than in CONT-G. Peak values were observed in both groups $24 \mathrm{~h}$ after PCI. In SIR-G, the concentration fell in the 1st and 4th weeks and remained low up to the 8th week, 4 weeks after sirolimus discontinuation. hs-CRP concentration in CONT-G returned to baseline levels after the 1 st week and remained stable at the 4 th and 8 th weeks. The changes in serum hs-CRP observed over time were not different for the two groups as determined by the repeated measures model $(F(3,18.8)=1.17, P=0.3477)$. However, after ANCOVA with adjustment for baseline, no differences were observed at $24 \mathrm{~h}$; a marginally significant difference was observed at week $1(P=0.0726)$, a significant difference at week $4(P=0.008)$ and a marginally significant difference at week $8(P=0.0975), 4$ weeks after treatment discontinuation.

MMP-9. In SIR-G, serum MMP-9 concentration fell steadily and achieved maximal reduction at 4 weeks. At 8 weeks, the concentration returned to pre-stenting levels. Contrary to what was observed for SIR-G, baseline MMP. 9 concentration rose continuously in CONT-G, reaching peak values at week 4 . There was a significant group vs time interaction $(F(3,59.7)=3.83, P=0.0141)$, indicating that changes in MMP-9 over time were different for the two groups. A simple effects test showed that SIR-G and CONT-G were different at 1 week $(-258.9 \pm 510$ vs +363 $\pm 438, \mathrm{P}=0.0030)$ and 4 weeks $(-352.9 \pm 455 v s+395.2$ $\pm 377, \mathrm{P}=0.0004)$. ANCOVA with adjustment for baseline levels revealed no difference at $24 \mathrm{~h}$, a marginally significant difference at week $1(P=0.0805)$, a significant difference at week $4(P=0.0062)$, and a marginally significant difference at week $8(P=0.0958)$.

MMP-2. Serum MMP-2 levels rose steadily in SIR-G, with the greatest increase being achieved at the 4th week. No significant change was observed in CONT-G. The group vs time effect was significant $(F(3,58)=3.51, P=0.0206)$. Simple effects tests revealed that the two groups were different only at week $4(+53.2 \pm 33.7$ vs $-14.2 \pm 49.2, \mathrm{P}=$ $0.0014)$. ANCOVA also revealed a significant difference at week $4(P=0.0037)$.

ICAM-1. Following $\mathrm{PCl}$, only non-significant variations were observed in both groups. CONT-G had significantly higher serum ICAM-1 levels than SIR-G at all times. There was no group vs time interaction $(F(3,16.3)=1.66, P=$ $0.2144)$. ANCOVA revealed significant differences at week $1(P=0.0047)$ and week $4(P=0.0096)$.

$P$-selectin. No significant changes in serum $P$-selectin concentration were observed in CONT-G. However, in SIR$\mathrm{G}$, a remarkable increase in P-selectin was observed at 8 weeks. There was a significant group vs time effect $(F(3$, $60)=3.19, P=0.0299$ ). Simple effects tests suggested a marginally significant difference between the two groups at week 8 (46.1 \pm 67.9 vs $5.8 \pm 23.7, P=0.0025)$ and ANCOVA showed a significant difference between the two groups at week $8(P=0.0025)$.

Serum MCP-1. The group vs time effect was nonsignificant $(F(3,18.7)=1.58, P=0.2283)$. Differences between groups were detected with ANCOVA at $24 \mathrm{~h}(\mathrm{P}$ $=0.0074$ ).

Serum TIMP-1. No significant group vs time effect was detected $(F(3,18.5)=0.57, P=0.6438)$. No significant difference was found with ANCOVA.

Serum IL-2sRa. There was no significant group vs time effect $(F(3,18.9)=0.55, P=0.6536)$. ANCOVA showed a significant difference between the two groups at $24 \mathrm{~h}(\mathrm{P}$ $=0.0015)$, a marginally significant difference at 1 week 
$(P=0.0781)$, and a significant difference at 8 weeks $(P$ $=0.0004)$.

\section{Discussion}

Sirolimus has been used systemically to prevent and treat cardiovascular disorders mainly because of its ability to inhibit smooth muscle cell proliferation. Its efficacy in treating restenosis has been successfully tested in animal models of balloon angioplasty (17) and in humans submitted to coronary artery stenting (12-15). We speculated that if oral sirolimus modifies the biological response to coronary artery stenting, it might also alter the expression of biomarkers related to the implantation of coronary stents and ISR. To our knowledge, this is the first investigation concerning the effect of oral sirolimus on biomarkers of the vascular

Table 2. Variations of serum biomarkers.

\begin{tabular}{|c|c|c|c|c|c|}
\hline Biomarker & Pre-PCl (ng/mL) & $\Delta 24 \mathrm{~h}$ & $\Delta$ 1st week & $\Delta 4$ th week & $\Delta$ 8th week \\
\hline \multicolumn{6}{|l|}{ hs-CRP } \\
\hline SIR-G & $2.9 \pm 4.6$ & $0.68 \pm 1.3$ & $-0.90 \pm 4.3^{*}$ & $-1.50 \pm 5.0^{\dagger}$ & $-1.73 \pm 4.3^{*}$ \\
\hline CONT-G & $0.5 \pm 0.3$ & $0.97 \pm 0.8$ & $0.03 \pm 0.3$ & $-0.19 \pm 0.4$ & $-0.01 \pm 0.7$ \\
\hline REF-G & $0.11 \pm 0.1$ & & & & \\
\hline \multicolumn{6}{|l|}{ MMP-2 } \\
\hline SIR-G & $201 \pm 56$ & $-9.0 \pm 51.4$ & $22.52 \pm 29.9$ & $53.2 \pm 33.7^{\ddagger}$ & $23.2 \pm 51.9$ \\
\hline CONT-G & $218 \pm 454$ & $-10.8 \pm 32.8$ & $16.58 \pm 49.6$ & $-14.2 \pm 49.2$ & $-3.9 \pm 63.2$ \\
\hline REF-G & $231 \pm 392$ & & & & \\
\hline \multicolumn{6}{|l|}{ MMP-9 } \\
\hline SIR-G & $825 \pm 546$ & $-2.2 \pm 385.7$ & $-258.9 \pm 510.6^{*}$ & $-352.9 \pm 455.9 \ddagger$ & $227 \pm 708^{*}$ \\
\hline CONT-G & $392 \pm 314$ & $325.7 \pm 257.6$ & $363 \pm 438.4$ & $395.2 \pm 377.2$ & $406.2 \pm 472.1$ \\
\hline REF-G & $437 \pm 226$ & & & & \\
\hline \multicolumn{6}{|l|}{ MCP-1 } \\
\hline SIR-G & $50 \pm 40$ & $-18.6 \pm 38.4^{\dagger}$ & $-5.90 \pm 67.9$ & $-18.47 \pm 43.6$ & $0.13 \pm 54.6$ \\
\hline CONT-G & $47 \pm 34$ & $26.3 \pm 34.7$ & $25.0 \pm 46.2$ & $21.2 \pm 53.5$ & $8.1 \pm 31.2$ \\
\hline REF-G & $108 \pm 123$ & & & & \\
\hline \multicolumn{6}{|l|}{ IL-2sRa } \\
\hline SIR-G & $553 \pm 349$ & $134.9 \pm 192.4^{\dagger}$ & $82.3 \pm 344.4^{*}$ & $122.5 \pm 311.1$ & $156.5 \pm 253.8^{\dagger}$ \\
\hline CONT-G & $369 \pm 227$ & $-25.1 \pm 139.8$ & $-16.9 \pm 167.6$ & $1.3 \pm 256.3$ & $-61.1 \pm 230.3$ \\
\hline REF-G & $600 \pm 1295$ & & & & \\
\hline \multicolumn{6}{|l|}{ P-selectin } \\
\hline SIR-G & $103 \pm 38$ & $-24.3 \pm 46.6$ & $-6.6 \pm 77.7$ & $-6.0 \pm 39.9$ & $46.1 \pm 67.9^{\dagger}$ \\
\hline CONT-G & $72 \pm 27$ & $-0.1 \pm 42.4$ & $16.0 \pm 66.6$ & $6.5 \pm 54.8$ & $5.8 \pm 23.7$ \\
\hline REF-G & $75 \pm 28$ & & & & \\
\hline \multicolumn{6}{|l|}{ TIMP-1 } \\
\hline SIR-G & $300 \pm 55$ & $7.1 \pm 69.5$ & $8.4 \pm 145.5$ & $-46.0 \pm 53.4$ & $-17.6 \pm 52.8$ \\
\hline CONT-G & $140 \pm 86$ & $18.4 \pm 45.9$ & $29.9 \pm 74.1$ & $59.5 \pm 241.4$ & $59.2 \pm 146.7$ \\
\hline REF-G & $232 \pm 46$ & & & & \\
\hline \multicolumn{6}{|l|}{ ICAM-1 } \\
\hline SIR-G & $214 \pm 53$ & $-3.4 \pm 35.1$ & $-13.1 \pm 49.7^{\dagger}$ & $-3.3 \pm 46.0^{\dagger}$ & $8.9 \pm 50.4$ \\
\hline CONT-G & $375 \pm 147$ & $-35.7 \pm 85.8$ & $-16.4 \pm 119.1$ & $3.8 \pm 138.4$ & $-35.3 \pm 124.5$ \\
\hline REF-G & $211 \pm 128$ & & & & \\
\hline
\end{tabular}

$\Delta($ delta $)=$ variations in relation to baseline (means \pm SD). Pre- $P C l=$ before percutaneous coronary intervention; hs-CRP = high sensitivity C-reactive protein; MMP-2 = matrix metalloproteinase 2; MMP$9=$ matrix metalloproteinase 9 ; MCP-1 = monocyte chemoattractant protein-1; IL-2sRa = soluble interleukin-2 receptor alpha; TIMP-1 = tissue inhibitor of MMP-1; ICAM-1 = intercellular adhesion molecule-1; SIR-G = sirolimus group; CONT-G = control group; REF-G = reference group. *Marginally significant differences between SIR-G and CONT-G in ANCOVA models with adjustment for baseline values. ${ }^{\dagger}$ Significant difference between SIR-G and CONT-G $(P<0.05)$ in ANCOVA models. łSignificant difference $(P<0.05)$ in both ANCOVA and mixed-model repeated measures analysis of variance. 
response in humans following coronary artery stenting.

In the present study, treatment with oral sirolimus was successful in keeping blood levels within the target range.
The drug regimen employed was similar to that used for prophylaxis of renal transplantation rejection, which is currently the only FDA-approved regimen for the clinical use
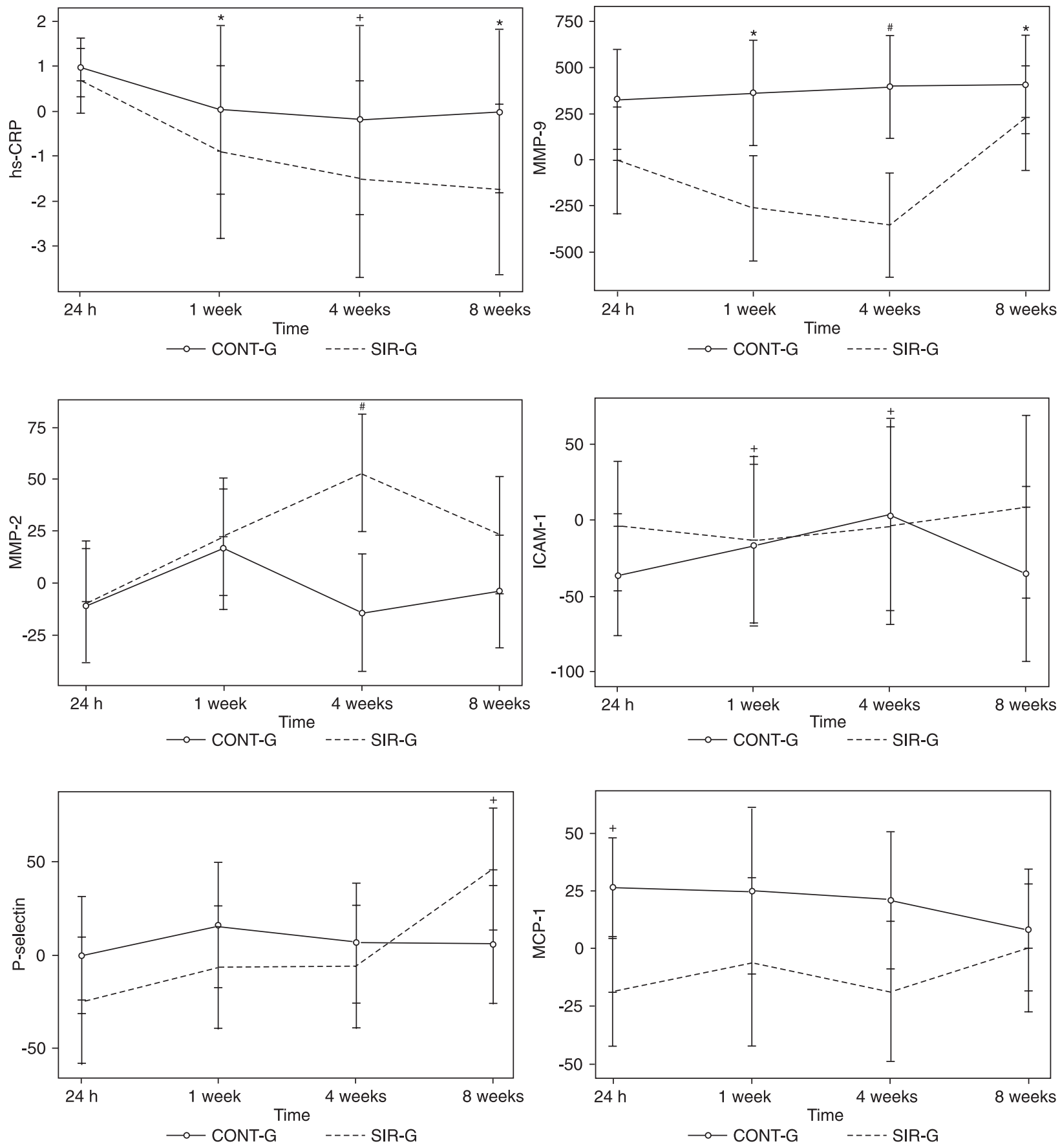

Figure 1. Variation (delta) of biomarker levels at follow-up. Data are reported as least square (LS) mean variation with $95 \%$ confidence intervals $(\Delta \% \pm 95 \% \mathrm{Cl})$. * Marginally significant differences between groups in ANCOVA models with adjustment for baseline values. +Significant difference between SIR-G and CONT-G $(P<0.05)$ in ANCOVA models. \#Significant difference $(P<0.05)$ in both ANCOVA and mixed-model repeated measures analysis of variance. For abbreviations, see legend to Table 2. 
of sirolimus in the United States (10). The same dosing scheme was also used by Waksman et al. (12) to prevent and treat ISR with good tolerability. It is important to note that the side effects were not severe, they were reversed after drug discontinuation and did not prevent the subsequent use of the full drug course.

Two biomarkers, MMP-9 and TIMP-1, had higher plasma concentrations at baseline in SIR-G than in CONT-G. During follow-up, SIR-G had higher mean concentrations of hs-CRP, IL-2sR $\alpha$ and P-selectin. These differences may be explained in part by the greater severity of coronary artery disease in the SIR-G group. SIR-G patients had a higher risk profile as compared to these CONT-G. More SIR-G patients had hypertension ( 91 vs $58 \%$ ), chronic renal failure (17 vs $8 \%$ ) and diabetes (42 vs 33\%). Moreover, 8 patients in SIR-G had ISR vs none in CONT-G. In fact, not only have hs-CRP and other inflammatory markers been described as tools to stratify coronary artery disease risk, but they are also known as indicators of the extent of the disease (18).

The results of our study corroborate the view that coronary artery stenting does indeed alter the systemic expression of inflammatory markers. hs-CRP concentration peaked $24 \mathrm{~h}$ after stenting and returned to baseline in the 1st week in both SIR-G and CONT-G. Although a difference between groups was not observed during follow-up in the repeated measures model, in the ANCOVA model we observed a trend toward greater reduction in SIR-G, which became significant at week 4 and lost significance at week 8 , after treatment discontinuation. Attenuation of the hs-CRP rise after $\mathrm{PCl}$ has been reported with systemic drugs such as statins (19), clopidogrel (20), angiotensin-converting enzyme inhibitors (21), and abciximab (22). Sirolimus and paclitaxel-eluting stents may also reduce hs-CRP concentration following $\mathrm{PCl}$ through local drug delivery (23).

$\mathrm{IL}-2 \mathrm{sRa}$ is considered to be a marker of lymphocyte activation (24) and may be elevated in stable (25) and unstable angina (26). ICAM-1 is elevated in stable atherosclerosis (27) and predicts rapid atherosclerosis progression (28). Despite these facts, no interaction between time and treatment was seen here in either group. However, contrary to what was expected, given that SIR-G patients were at higher risk for restenosis, ICAM-1 concentrations were significantly lower in SIR-G at all times. Besides, the ANCOVA model revealed significant differences for the variations in the presence of sirolimus treatment and no difference after its discontinuation, a pattern similar to that of hs-CRP. Therefore, a reduction of ICAM-1 levels by oral sirolimus seems plausible. Sirolimus reduces the expression of ICAMs and other adhesion molecules present in endothelial cells (29) and suppresses the proinflammatory and pro-adhesive gene expression seen after angioplasty in animal models (30). Some differences were seen in IL-2sR $\alpha$ after adjustment, but apparently they were not correlated with treatment.
P-selectin is an adhesion molecule that is elevated in acute coronary syndromes (31). Its inhibition reduces neointima formation in rats submitted to balloon angioplasty (32). In the present study, P-selectin levels exhibited a remarkably greater increase at 8 weeks in SIR-G. Such increase was evident in ANCOVA and was corroborated by a trend towards an increase in the repeated measures model at the same time. This elevation took place after sirolimus discontinuation, suggesting a suppressive effect of this drug on P-selectin expression. Sirolimus has been shown to reduce the expression of $\mathrm{P}$-selectin in human cell cultures (28). Although clopidogrel pretreatment reduces the levels of P-selectin after $\mathrm{PCl}$ (33), the hypothesis that clopidogrel discontinuation after 4 weeks could have caused $\mathrm{P}$-selectin levels to rise is unlikely, because a significant change in P-selectin variation was not observed in CONT$G$ at week 8 .

MMPs play important roles in biological processes involving extracellular matrix turnover or repair, including restenosis $(34,35)$. Sirolimus is known to inhibit the activity of genes associated with extracellular matrix production (36). In the present study, we observed a progressive fall in the serum levels of MMP-9 after coronary stenting in SIR-G and 4 weeks after sirolimus discontinuation, serum levels of MMP-9 were similar to that observed before stent implantation. In turn, serum MMP-9 concentration increased continuously in CONT-G. MMP-9 is an independent risk factor for ISR, and multiple ISR sites have a stronger correlation with higher serum levels of MMP-9 than a single ISR site or no ISR (37). In contrast, serum MMP-2 concentrations increased in SIR-G, with the greatest variation at 4 weeks, when there was a significant difference between the two groups. These findings are consistent with data reported by $\mathrm{Ge}$ et al. (38) indicating that serum levels of MMP-9 but not MMP-2 correlate positively with angiographic late lumen loss six months after stenting. Therefore, MMP-9 levels after $\mathrm{PCl}$ could serve as a marker of the anti-restenotic action of systemic sirolimus and other antiproliferative drugs. On the other hand, the inhibition of MMP-9 activity, which has been associated with decreased migration of smooth muscle cells to the intima after balloon angioplasty in animal models (39), could be an important component of the anti-restenotic action of sirolimus. However, to our knowledge, there have been no reports of such an action by sirolimus.

Serum MCP-1 and TIMP-1 did not differ between groups except for the variation in MCP-1 at $24 \mathrm{~h}$. MCP-1 elevation after $\mathrm{PCI}$ has been reported to be independently associated with restenosis (40).

The main limitations of the present study are the small sample size, large intragroup variation in biomarker concentrations and the differences in risk profile between the two treatment groups evaluated. Especially for hs-CRP, MMP-9, ICAM-1, and P-selectin, a randomized study with less variability between groups will be necessary to confirm our findings. Also, it is not clear whether the present results 
would be maintained if drug regimens with lower doses or a shorter course were used, as employed by previous investigators $(13,15)$.

In conclusion, when analyzing the systemic inflammatory response to coronary stenting in humans, a reduction of MMP-9 concentration was evident with oral sirolimus. The fact that MMP-9 concentration increased again 4 weeks after discontinuation of sirolimus suggests that the drug was responsible for the decrease in MMP-9 levels. The marked rise of $\mathrm{P}$-selectin following discontinuation of sirolimus and the consistently lower concentration of ICAM-1 in the group treated with oral sirolimus strongly suggest a drug-related

\section{References}

1. Clausell N, de Lima V, Molossi S, Liu P, Turley E, Gotlieb AI, et al. Expression of tumour necrosis factor alpha and accumulation of fibronectin in coronary artery restenotic lesions retrieved by atherectomy. Br Heart $J$ 1995; 73: 534-539.

2. Moreno PR, Bernardi VH, Lopez-Cuellar J, Newell JB, McMellon C, Gold HK, et al. Macrophage infiltration predicts restenosis after coronary intervention in patients with unstable angina. Circulation 1996; 94: 3098-3102.

3. Lima VC, Gotlieb AI, Clausell N, Molossi S, Kimball BP, Cohen EA, et al. Analysis of atherosclerotic plaques obtained by coronary atherectomy: Foam cells correlated positively with subsequent restenosis. Cardiovasc Pathol 1996; 5: 265-269.

4. Farb A, Sangiorgi G, Carter AJ, Walley VM, Edwards WD, Schwartz RS, et al. Pathology of acute and chronic coronary stenting in humans. Circulation 1999; 99: 44-52.

5. Gaspardone A, Crea F, Versaci F, Tomai F, Pellegrino A, Chiariello $\mathrm{L}$, et al. Predictive value of $\mathrm{C}$-reactive protein after successful coronary-artery stenting in patients with stable angina. Am J Cardiol 1998; 82: 515-518.

6. Buffon A, Liuzzo G, Biasucci LM, Pasqualetti P, Ramazzotti V, Rebuzzi AG, et al. Preprocedural serum levels of C-reactive protein predict early complications and late restenosis after coronary angioplasty. J Am Coll Cardiol 1999; 34: 15121521.

7. Dibra A, Mehilli J, Braun S, Hadamitzky M, Baum H, Dirschinger J, et al. Inflammatory response after intervention assessed by serial C-reactive protein measurements correlates with restenosis in patients treated with coronary stenting. Am Heart J 2005; 150: 344-350.

8. Welt FG, Rogers C. Inflammation and restenosis in the stent era. Arterioscler Thromb Vasc Biol 2002; 22: 1769-1776.

9. Marx SO, Marks AR. Bench to bedside: the development of rapamycin and its application to stent restenosis. Circulation 2001; 104: 852-855.

10. Saunders RN, Metcalfe MS, Nicholson ML. Rapamycin in transplantation: a review of the evidence. Kidney Int 2001; 59: 3-16.

11. Kastrati A, Mehilli J, Pache J, Kaiser C, Valgimigli M, Kelbaek $\mathrm{H}$, et al. Analysis of 14 trials comparing sirolimus-eluting stents with bare-metal stents. N Engl J Med 2007; 356: 1030-1039.

12. Waksman R, Ajani AE, Pichard AD, Torguson R, Pinnow E, suppression of these two biomarkers. The possibility of the suppression of hs-CRP by oral sirolimus cannot be ruled out. This leads to the hypothesis that the mechanism of inhibition of in-stent restenosis by oral sirolimus combines anti-proliferative effects and modulation of the inflammatory response to $\mathrm{PCl}$, with the latter being achieved through a reduction in the expression of adhesion molecules that are important for the inflammatory process.

\section{Acknowledgments}

Research supported by FAPESP (\#03/02946-7).
Canos D, et al. Oral rapamycin to inhibit restenosis after stenting of de novo coronary lesions: the Oral Rapamune to Inhibit Restenosis (ORBIT) study. J Am Coll Cardiol 2004; 44: 1386-1392.

13. Hausleiter J, Kastrati A, Mehilli J, Vogeser M, Zohlnhofer $\mathrm{D}$, Schuhlen $\mathrm{H}$, et al. Randomized, double-blind, placebocontrolled trial of oral sirolimus for restenosis prevention in patients with in-stent restenosis: the Oral Sirolimus to Inhibit Recurrent In-stent Stenosis (OSIRIS) trial. Circulation 2004; 110: 790-795.

14. Brito FS Jr, Rosa WC, Arruda JA, Tedesco H, Pestana JO, Lima VC. Efficacy and safety of oral sirolimus to inhibit instent intimal hyperplasia. Catheter Cardiovasc Interv 2005; 64: 413-418.

15. Rodriguez AE, Granada JF, Rodriguez-Alemparte M, Vigo $\mathrm{CF}$, Delgado J, Fernandez-Pereira C, et al. Oral rapamycin after coronary bare-metal stent implantation to prevent restenosis: the Prospective, Randomized Oral Rapamycin in Argentina (ORAR II) Study. J Am Coll Cardiol 2006; 47: 1522-1529.

16. Svensson JO, Brattstrom C, Sawe J. Determination of rapamycin in whole blood by HPLC. Ther Drug Monit 1997; 19: 112-116.

17. Gallo R, Padurean A, Jayaraman T, Marx S, Roque M, Adelman S, et al. Inhibition of intimal thickening after balloon angioplasty in porcine coronary arteries by targeting regulators of the cell cycle. Circulation 1999; 99: 2164-2170.

18. Erren M, Reinecke $H$, Junker R, Fobker $M$, Schulte $H$, Schurek JO, et al. Systemic inflammatory parameters in patients with atherosclerosis of the coronary and peripheral arteries. Arterioscler Thromb Vasc Biol 1999; 19: 23552363.

19. Chan AW, Bhatt DL, Chew DP, Reginelli J, Schneider JP, Topol EJ, et al. Relation of inflammation and benefit of statins after percutaneous coronary interventions. Circulation 2003; 107: 1750-1756.

20. Merino A, Gaya A, Segura I, Calvo J, Imizcoz C, Berenguel $A$, et al. Platelet aggregation inhibition blocks C-reactive protein and interleukin-6 (IL-6) elevation after the coronary angioplasty: effect of the $-174 \mathrm{G} / \mathrm{C}$ IL-6 gene polymorphism. Am J Cardiol 2004; 94: 1300-1303.

21. Schieffer B, Bunte C, Witte J, Hoeper K, Boger RH, Schwedhelm E, et al. Comparative effects of AT1-antagonism and 
angiotensin-converting enzyme inhibition on markers of inflammation and platelet aggregation in patients with coronary artery disease. J Am Coll Cardiol 2004; 44: 362-368.

22. Lincoff AM, Kereiakes DJ, Mascelli MA, Deckelbaum LI, Barnathan ES, Patel KK, et al. Abciximab suppresses the rise in levels of circulating inflammatory markers after percutaneous coronary revascularization. Circulation 2001; 104: 163-167.

23. Gibson CM, Karmpaliotis D, Kosmidou I, Murphy SA, Kirtane AJ, Budiu D, et al. Comparison of effects of bare metal versus drug-eluting stent implantation on biomarker levels following percutaneous coronary intervention for non-STelevation acute coronary syndrome. Am J Cardiol 2006; 97: 1473-1477.

24. Rubin LA, Nelson DL. The soluble interleukin-2 receptor: biology, function, and clinical application. Ann Intern Med 1990; 113: 619-627.

25. Takeshita S, Isshiki T, Ochiai M, Ishikawa T, Nishiyama $Y$, Fusano $\mathrm{T}$, et al. Systemic inflammatory responses in acute coronary syndrome: increased activity observed in polymorphonuclear leukocytes but not T lymphocytes. Atherosclerosis 1997; 135: 187-192.

26. Liuzzo G, Goronzy JJ, Yang H, Kopecky SL, Holmes DR, Frye RL, et al. Monoclonal T-cell proliferation and plaque instability in acute coronary syndromes. Circulation 2000; 101: 2883-2888.

27. Guray U, Erbay AR, Guray Y, Yilmaz MB, Boyaci AA, Sasmaz $\mathrm{H}$, et al. Levels of soluble adhesion molecules in various clinical presentations of coronary atherosclerosis. Int $\mathrm{J}$ Cardiol 2004; 96: 235-240.

28. Zouridakis E, Avanzas P, Arroyo-Espliguero R, Fredericks S, Kaski JC. Markers of inflammation and rapid coronary artery disease progression in patients with stable angina pectoris. Circulation 2004; 110: 1747-1753.

29. Wood SC, Bushar G, Tesfamariam B. Inhibition of mammalian target of rapamycin modulates expression of adhesion molecules in endothelial cells. Toxicol Lett 2006; 165: 242249.

30. Nuhrenberg TG, Voisard R, Fahlisch F, Rudelius M, Braun J, Gschwend J, et al. Rapamycin attenuates vascular wall inflammation and progenitor cell promoters after angioplasty. FASEB J 2005; 19: 246-248.
31. Parker C III, Vita JA, Freedman JE. Soluble adhesion molecules and unstable coronary artery disease. Atherosclerosis 2001; 156: 417-424.

32. Hayashi S, Watanabe N, Nakazawa K, Suzuki J, Tsushima $\mathrm{K}$, Tamatani $\mathrm{T}$, et al. Roles of P-selectin in inflammation, neointimal formation, and vascular remodeling in ballooninjured rat carotid arteries. Circulation 2000; 102: 17101717.

33. Quinn MJ, Bhatt DL, Zidar F, Vivekananthan D, Chew DP, Ellis SG, et al. Effect of clopidogrel pretreatment on inflammatory marker expression in patients undergoing percutaneous coronary intervention. Am J Cardiol 2004; 93: 679-684.

34. Dollery CM, McEwan JR, Henney AM. Matrix metalloproteinases and cardiovascular disease. Circ Res 1995; 77: 863-868.

35. Hojo Y, Ikeda U, Katsuki T, Mizuno O, Fujikawa H, Shimada $\mathrm{K}$. Matrix metalloproteinase expression in the coronary circulation induced by coronary angioplasty. Atherosclerosis 2002; 161: 185-192.

36. Zohlnhofer D, Nuhrenberg TG, Neumann FJ, Richter T, May AE, Schmidt R, et al. Rapamycin effects transcriptional programs in smooth muscle cells controlling proliferative and inflammatory properties. Mol Pharmacol 2004; 65: 880889.

37. Jones GT, Kay IP, Chu JW, Wilkins GT, Phillips LV, McCormick $M$, et al. Elevated plasma active matrix metalloproteinase-9 level is associated with coronary artery in-stent restenosis. Arterioscler Thromb Vasc Biol 2006; 26: e121e125.

38. Ge J, Shen C, Liang C, Chen L, Qian J, Chen H. Elevated matrix metalloproteinase expression after stent implantation is associated with restenosis. Int J Cardiol 2006; 112: 8590.

39. Bendeck MP, Irvin C, Reidy MA. Inhibition of matrix metalloproteinase activity inhibits smooth muscle cell migration but not neointimal thickening after arterial injury. Circ Res 1996; 78: 38-43.

40. Cipollone F, Marini M, Fazia M, Pini B, lezzi A, Reale M, et al. Elevated circulating levels of monocyte chemoattractant protein-1 in patients with restenosis after coronary angioplasty. Arterioscler Thromb Vasc Biol 2001; 21: 327-334. 